\title{
El alfabeto latino como estímulo para la alfabetidad visual. Diseño, formación del profesorado y derivas tipográficas urbanas
}

\section{Resumen}

Esta investigación ${ }^{1}$ nace de un proceso de intervención en las aulas universitarias de formación del profesorado. El artículo genera un estudio exploratorio y descriptivo de las posibilidades educativas del alfabeto como forma visual, a partir del cual se presenta un estudio de caso en el que se analizan dos talleres que se imparten a varios grupos de alumnado de la Facultat de Magisteri de la Universitat de València. El objetivo de la investigación consiste en reflexionar a partir de prácticas artísticas y de diseño gráfico, incorporando cuestiones relativas a la alfabetidad visual, el diseño y el patrimonio, especialmente desde el taller de gráfica y las derivas tipográficas urbanas, mediante la Investigación Educativa Basada en Artes (ABER, Arts Based Educational Research). La recogida de datos se hace a través de la práctica docente, usando instrumentos de evaluación propios del estudio de caso, como diagnósticos y trabajo creativo. Por la reflexión que genera la práctica en educación artística y la educación en diseño, utilizamos el debate como fuente de argumentación, tratando asimismo cuestiones de género y diversidad sexual. Abogamos por incorporar experiencias personales con el fin de formar maestros y maestras más conscientes del respeto a la diversidad y la educación inclusiva. Entre los resultados conseguidos, destacar la utilización del diseño como escenario importante en la formación del profesorado para una alfabetidad visual, así como el cuestionamiento de estereotipos sociales, superando los tabúes convencionales, propiciando espacios creativos de discusión, y dando tanta importancia al proceso como a los resultados finales.

\section{Ricard Huerta}

Doctorado en Bellas Artes.

Universitat de València, Valencia, España.

Correo electrónico:

ricard.huerta@uv.es

ำ orcid.org/0000-0002-1430-3198

Google Scholar

Recibido: febrero 16 de 2021 Aprobado: junio 23 de 2021

Palabras clave:

alfabetidad visual, creatividad, diseño, formación del profesorado, educación inclusiva.

\footnotetext{
'Esta investigación forma parte del proyecto $1+\mathrm{D}+\mathrm{i}$ "Sensibilización en igualdad de género y diversidad sexual mediante intervenciones artísticas en contextos universitarios", con financiación de la Generalitat Valenciana GVA a través de la Conselleria de Innovación, Universidades, Ciencia y Sociedad Digital (Referencia: GV/2020/069).
} 


\section{The Latin alphabet as a stimulus for visual literacy. Design, teacher training and urban typographic drifts}

\begin{abstract}
This research originated from a process of intervention in university classrooms for teacher training. The article generates an exploratory and descriptive study of the educational possibilities of the alphabet as a visual form from which a case study is presented in which two workshops that are given to various groups of students of the Faculty of Magisteri at Universitat de Valencia. The objective of the research is to reflect on artistic practices and graphic design incorporating issues related to visual literacy, design and heritage, especially from the graphic workshop and urban typographic drifts, through Arts Based Educational Research, $A B E R$. Data collection is done through teaching practice using assessment tools typical of the case study such as diagnoses and creative work. Due to the reflection generated by the practice in art education and education in design, it is necessary to use the debate as a source of argument, also addressing issues of gender and sexual diversity. The advocacy is to incorporate personal experiences in order to train teachers who are more aware of respect for diversity and inclusive education. Among the results, the use of design as an important setting in teacher training for visual literacy is highlighted as well as the questioning of social stereotypes, overcoming conventional taboos, fostering creative spaces for discussion, and giving as much importance to the process as to the final results.
\end{abstract}

Key words:

visual literacy, creativity, design, teacher training, inclusive education. 


\section{Introducción}

Partimos de la base de que el alfabeto es una tecnología milenaria que está muy presente en todas las actividades cotidianas que generamos, tanto en el trabajo como en nuestros hogares, y desde luego también en el entorno online. A partir del reconocimiento de la importancia que adquiere el alfabeto en nuestras vidas, debemos asumir que, al menos en lo referido a educación, el alfabeto forma parte de las dinámicas que envuelven a la enseñanza de las lenguas, y por tanto se hace un uso de la escritura muy vinculado al estudio del lenguaje verbal. Se nos enseña a leer y a escribir para que conozcamos y utilicemos las letras como extensiones del lenguaje oral, de modo que en la escritura quedan plasmados los fonemas para reflejar gráficamente los usos de las expresiones orales. Así las cosas, observamos que en ningún ciclo educativo (infantil, primaria, secundaria, universidad) existe un interés por transmitir al alumnado las posibilidades gráficas del alfabeto latino. Tampoco se enseña su historia, su capacidad comunicativa visual, o sus recursos expresivos y artísticos (Panciroli, 2016). Entendemos que debe superarse esta falta de atención desde las instancias educativas hacia la práctica del diseño y la calidad visual del alfabeto latino, de modo que incorporemos al currículum escolar el estudio del alfabeto y la tipografía como entidades visuales de primer orden.

Para superar este vacío curricular y empezar a dar forma al conocimiento de las posibilidades gráficas del alfabeto como artefacto visual, proponemos iniciar el proceso centrándonos en la formación del profesorado, incidiendo especialmente en la formación inicial de maestros y maestras. El hecho de comenzar a difundir el conocimiento del alfabeto entre futuros docentes supone incorporar a los estudios de grado universitario una serie de elementos formativos entre los que se incluirían la historia de la escritura (Briggs y Burke, 2002), la caligrafía, la tipografía y el diseño de letras (Fetter, 2019). Además de generar formación teórica al respecto, resultará fundamental introducir talleres 
de diseño y experiencias creativas, mediante las cuales los futuros docentes puedan poner en práctica sus habilidades gráficas y progresar en su pericia y conocimiento de los materiales, sin perder nunca de vista la deriva digital (Álvarez y Cabrera, 2020).

Queremos incidir en la importancia del estudio de las letras como lenguaje visual, ya que las letras son imágenes, y contienen una serie de posibilidades gráficas y educativas que las hacen especialmente sensibles para generar conocimiento situado, fomentando al mismo tiempo la creatividad y la interculturalidad (Said-Valbuena, 2019). Nuestra experiencia en las aulas nos permite abordar la cuestión desde la práctica. Es así como gestionamos la incorporación de la alfabetización visual, combinando las aportaciones teóricas con las actividades que surgen en el taller, de modo que los aprendizajes se convierten en experiencias vividas. Se fomenta la creatividad de cada participante al impulsar procesos y resultados en el taller de diseño (Bernal, 2016). Otro aspecto destacable es la incorporación de los paseos urbanos como ejercicio estético, tal y como sugiere Francesco Careri (2005):

La deriva letrista desarrollaba la lectura subjetiva de la ciudad iniciada por los surrealistas, pero se proponía transformarla en un método objetivo de exploración de la ciudad: el espacio urbano era un terreno pasional objetivo, y no sólo subjetivo e inconsciente. (p. 92)

Todas estas iniciativas nos han deparado resultados positivos, ya que la investigación pretende demostrar la necesidad de incorporar a la formación de docentes los conocimientos sobre el alfabeto y el estudio del diseño gráfico con entidad pedagógica.

\section{Método}

Esta investigación es de corte cualitativo, a partir de una metodología híbrida en la que predomina el estudio de caso (Stake, 2005), incorporando la Investigación 
Educativa Basada en Artes (Rolling, 2017a). Nuestro interés por mejorar la formación del profesorado en materia de alfabetidad visual nos impulsa a revisar y cuestionar tanto nuestras prácticas docentes como las formas en que generamos conocimiento, los modos como nos relacionamos y aprendemos (Pallarès, 2020). A partir de este deseo por avanzar, incorporamos experiencias y saberes desde las alteridades, dando paso a una mayor valoración de lo cotidiano, de lo diverso, e incluso de lo marginal. Todo ello nos lleva a pensar en las posibilidades reflexivas, creativas y de construcción de conocimiento en los entornos de aprendizaje (Huerta et al., 2017). Con estas inquietudes, es posible abordar dimensiones colaborativas de los procesos de aprendizaje y concebir las prácticas artísticas dentro del aula como un espacio creativo. Logramos así favorecer el diálogo con las discusiones sociales y con las propuestas de las pedagogías críticas, mediante acciones pedagógicas situadas, más cercanas a los usuarios, desde la praxis humanizada y la participación implicada (Arriaga et al., 2018). Abrimos procesos formativos universitarios que permiten crear un tejido colectivo entre quienes conforman los espacios de aprendizaje, para discutir sobre elementos de la inclusión de la diferencia o la consideración de las experiencias compartidas (Hernández y Sancho-Gil, 2015). Esto nos permite problematizar sobre las prácticas docentes que nos afectan en todas las dimensiones, y vivenciar las experiencias que constituyen el espacio de aprendizaje, a través de una pedagogía que se expande y cruza límites fronterizos. Para Elliot Eisner (2004), el aprendizaje situado se define en relación al modo como las personas se sitúan en un contexto social y material, entendido como cultura, que enseña y que está en constante proceso de cambio.

Atendemos también a las propuestas coeducativas, vinculadas a la igualdad, como una forma coherente de situar el pensamiento feminista pedagógico, incorporando elementos de la cultura de las mujeres, especialmente aquellos que tienden a disminuir la violencia, aumentar el respeto, y también a fomentar 
las relaciones entre las personas y la conservación y el cuidado de quienes más lo necesitan (Zafra, 2017). En el caso del presente artículo, que aborda una experiencia de investigación llevada a cabo en las aulas, nos posicionamos desde los parámetros de la pedagogía crítica, ya que nos interesa tanto la incorporación del conocimiento sobre la imagen del alfabeto en el conjunto de la necesaria alfabetidad visual (Duncum, 2015), como la voluntad de promover una enseñanza inclusiva, basada en el respeto y la participación de todas las personas involucradas en los procesos de enseñanza (Pallarès y Lozano, 2020). Desde nuestra reflexión tiene cabida la problematización del espacio escolar y sus relaciones de poder, en tanto que son reflejo de nuestra sociedad, que reproduce situaciones de desigualdad y sigue utilizando estereotipos sociales discriminatorios en el espacio de aprendizaje (Sancho-Gil y Hernández, 2018). Nuestras reflexiones apuntan hacia la visibilidad de las diversidades sexuales y de género en el proceso, por lo que la toma de decisiones en cuanto a qué y cómo abordar el proceso de aprendizaje dependerá del propio contexto (Pallarès, 2014).

La posibilidad de concebir una escuela desde planteamientos que incluyan los saberes vinculados a las Humanidades, entre los cuales estaría la cultura escrita en tanto que variante de la imagen, son viables si el espacio escolar específico puede concretar cuáles son las propuestas que se deben abordar (Miranda et al., 2017). La concepción de la escuela como un entorno muy impregnado por la visualidad nos permite avanzar hacia la cultura visual, incorporando elementos que nacen de presupuestos sociológicos, semióticos y artísticos, articulando la práctica docente desde la innovación educativa, considerando las singularidades del alumnado universitario de Magisterio, factores clave a la hora de proponer una investigación significativa que suponga avances en la formación del profesorado (Lobovikov-Katz, 2019). 
Conviene tener muy en cuenta los intereses del alumnado, considerando sus propias experiencias, atendiendo a sus narrativas y conocimiento en contextos singulares para aprender (Ramon, 2019). Por ello, activamos prácticas artísticas de visualización entre cuerpo y objeto en entornos de mediación pedagógica. Concebir la educación desde un planteamiento crítico permite problematizar los elementos de discriminación en el espacio educativo (López, 2019). Incluso, cuando contemplamos acciones concretas de valoración de la diversidad o la incorporación de referentes LGTB, existen numerosos niveles de problematización que nos llevan a identificar relaciones y discursos del poder (Chung, 2007), así como otros muchos elementos que permanecen invisibilizados y que no se abordan en tanto no exista una voluntad legítima de cambiar y mejorar el ámbito educativo (Ramon, 2017).

Defendemos asimismo las experiencias artísticas como mediadoras para la transformación social, puesto que el conocimiento de nuestro entorno es el factor idóneo para mejorarlo (Duncum, 2008). Articular el discurso en torno al conocimiento de la escritura como entidad visual permite abrazar numerosos factores culturales, que van desde la utilización de tipografías para diseñar, hasta el reconocimiento del entorno próximo desde las tipografías urbanas (Dos Reis, 2016). Si todo ello va acompañado de un enfoque crítico, en el que juega un papel determinante la lucha contra la discriminación, entonces auspiciamos un nuevo concepto del territorio escolar como lugar que puede posibilitar procesos reflexivos y de problematización de las cuestiones sociales (Giroux, 1990). Incorporando este tipo de acciones generamos debates que afectan al estudiantado de manera directa, como la discriminación por género, la marginación o la desigualdad. Esto nos permite abordar algunas problemáticas que permean desde la sociedad de diversas maneras, incluyendo como propuesta la utilización de prácticas artísticas (Huerta y Domínguez, 2020). 
Se trata de prácticas que permiten el desarrollo de procesos de reflexión y experiencia, mediante lenguajes que suponen la construcción del conocimiento artístico, donde además de favorecer resultados, incide el proceso de creación, así como las relaciones y la práctica artística en sí misma (Hamlin y Fusaro, 2018). Esto permite dar valor a la experiencia artística como un acto mediador entre la expresión y las discusiones sociales actuales, con un sentido político y una vivencia transformadora (Alegría et al., 2018). Asimismo, se genera un acto mediador transformativo desde la práctica artística, forjando procesos creativos, que implican a la sociedad y la cultura que habitamos, considerando la creación como un elemento generador de pensamiento y un espacio de libertad, produciendo conocimiento desde la propia práctica, construyendo creaciones artísticas desde el diseño (Munari, 2019). De este modo, la educación artística se convierte en motor de transformación social (Huerta, 2020a), que atiende de modo especial tanto a los intereses del alumnado como del profesorado. En este sentido, planteamos la necesidad de hacer propuestas creativas considerando las prácticas artísticas desde una perspectiva que incluye la concepción del arte para la transformación y mejora social (Huerta, 2019). Es posible incorporar elementos que transitan desde las artes y el diseño hacia los espacios formativos, y que fomenten una sociedad basada en el respeto, la colaboración y la equidad (Huerta, 2017). Según esto, abordamos un modelo de investigación que concibe las prácticas artísticas como agentes articuladores de subjetividades, vinculadas a problemáticas de género y a cuestiones de índole social.

\section{Participantes, instrumento y procedimiento}

El enfoque de la investigación se define como cualitativo y tiene un carácter exploratorio, debido a la novedad de las temáticas abordadas en este contexto particular, y a la ausencia de tratamiento previo desde la perspectiva que lo abordamos, lo cual permite definir la investigación como un estudio de caso 
exploratorio (Yin, 1994). Conviene señalar que la metodología de trabajo utilizada en esta investigación está contextualizada desde el ejercicio de la docencia universitaria, un estudio en el que han participado cuatro grupos de alumnado, sumando un total de 200 participantes. Se trata de alumnado que estudia el grado de Maestro/a en Educación Primaria. Los estudios de Magisterio en la Universitat de València disponen de varias "menciones" (podríamos denominarlas especialidades). El alumnado que participa activamente en esta investigación está matriculado en la mención de "Arte y Humanidades", y se ha inscrito en la asignatura optativa "Propuestas Didácticas en Educación Artística". Por tanto, estamos hablando de una tipología de alumnado que tiene interés por las artes y que confía en sus posibilidades educativas (Hernández, 2008).

De nuestras propuestas para la enseñanza de las artes visuales se desprende la necesidad de articular una investigación que se hace partiendo del contexto en el que surge, estableciendo dinámicas de diálogo crítico en el espacio formativo. La unidad de análisis es una materia de 3er curso del Grado Universitario de Maestro/a de Educación Primaria, con una edad promedio del alumnado de 22 años y un total de 200 personas participantes. Se considera esta unidad de análisis por dos razones: 1) El contenido curricular de la asignatura "Propuestas Didácticas en Educación Artística" que permite una articulación entre el enfoque de inclusión y la disciplina, y 2) El encuentro con la práctica de las artes por parte de la mayoría del alumnado implicado en la investigación. Las clases incluyen debates, propuestas y soluciones formales a las problemáticas, partiendo de la reflexión, y dinamizando las actividades mediante talleres creativos y participativos, en los que surgen cuestiones como: la consideración de las problemáticas; preocupaciones, imaginarios y prejuicios del alumnado; el desarrollo de actividades artísticas; y una reflexión artística en el contexto de la visualidad (Santamaría, 2019). El estudio se ha realizado durante los cursos 2019-2020 y 2020-2021, lo cual ha supuesto un esfuerzo considerable de 
organización y adecuación, al tener que pasar la actividad a formato online, a causa de la pandemia (Huerta y Alonso-Sanz, 2020).

Las técnicas de recolección y construcción de los datos se definen por: a) diagnósticos al inicio de las actividades para definir los conocimientos previos del curso respecto de las temáticas que se abordarían; y b) desarrollo de talleres en los que el alumnado realiza sus diseños o bien genera imágenes del entorno. El procedimiento de análisis se establece en tanto que discusión analítica de los datos recogidos, desde una perspectiva de investigación de tipo cualitativo. En todos los casos se establecen categorías de análisis emergentes del diagnóstico inicial. Se lleva a cabo una prospección de los datos desde la construcción de una matriz de doble entrada en Microsoft Excel. Las experiencias que seleccionamos para elaborar el presente trabajo se organizan a través de un eje que articula el conjunto de las actividades, ya que la intención de convertir el alfabeto latino en territorio propicio para fomentar la alfabetidad visual evidencia una serie de parámetros de tipo educativo, a saber: la posibilidad de aprender sobre las imágenes a través de la imagen de las letras (Huerta, 2010), y la oportunidad de ofrecer una educación inclusiva con base en el conocimiento de las leyes que definen la tecnología milenaria del alfabeto. Desde el principio se tiene muy en cuenta lo que el alumnado ya sabe, puesto que sus conocimientos abrirán caminos inimaginables.

\section{Resultados}

Las actividades propuestas que hemos seleccionado para estudiarlas en su proceso y analizar resultados son dos de los trabajos por proyectos que se ofrecen al alumnado en la materia "Propuestas Didácticas en Educación Artística". En primer lugar estudiamos el proyecto "Identidades", con el que acercamos al alumnado universitario de la carrera de Magisterio al conocimiento del alfabeto desde la práctica, ya que realizan un ejercicio que 
consiste en diseñar su propio "Exlibris". El segundo proyecto es el titulado "Ciudad", mediante el cual el alumnado elabora un portfolio con imágenes de diferentes entornos urbanos, centrándose en las tipografías. Pasamos a describir y analizar cada caso.

\section{Caso 1. Proyecto "Identidades"}

Al iniciar las explicaciones del proyecto "Identidades", vinculamos la escritura con las manifestaciones artísticas. El arte en todas las épocas incorpora textos (Barthes, 1986). En la pintura gótica son habituales las filacterias, ocupando espacios compositivos en las pinturas y otras manifestaciones artísticas. Entre los grabadores siempre hubo especialistas en escritura. A lo largo del siglo XX irrumpe con fuerza la presencia de letras en las obras de arte, desde el cubismo hasta los movimientos surrealista, dada, futurismo y déco. Artistas como Klee, Picabia, Braque, Picasso, Gris, Magritte o Erté incorporan letras y textos de forma habitual en sus obras, así como Kurt Schwitters, Raoul Hausmann, y los miembros de la Bauhaus. Los artistas de los movimientos Situacionista y Pop Art aplican letras y textos a sus creaciones, como vemos en las pinturas de Andy Warhol, Robert Indiana, Cy Twombly, Robert Rauschenberg o Jasper Johns. Al hablar a nuestro alumnado de estos artistas y movimientos a través de los textos que incorporan, les estamos animando a generar recursos educativos para el futuro, puesto que van a ser docentes, y necesitan argumentos para unir arte, diseño y educación (Benjamin, 2003). No perdamos de vista que los futuros maestros y maestras serán quienes enseñarán a leer y a escribir a su alumnado (Dewey, 2008). También, incorporamos a las clases teóricas los diseños tradicionales de artesanía de letreros, que han dado paso a lo que podríamos denominar una verdadera efervescencia del lettering, que ha puesto de moda la caligrafía creativa y el uso de letras tanto en decoración como en terapias, relax o entretenimiento. 
Tras estas primeras sesiones formativas pasamos al taller en el que el alumnado realiza su propio exlibris. Como la mayoría de mi alumnado considera que "no sabe dibujar", resulta curioso que al preguntarles si saben escribir, todos responden afirmativamente. Les explico que "escribir" también es "dibujar". Cuando se trata de incorporar el arte y el diseño al bagaje del profesorado, partir de lo que ya conocen simplifica mucho la tarea. Saben escribir, porque lo aprendieron en la escuela, pero se manifiestan "poco conocedores" del arte, porque durante sus años escolares no tuvieron prácticamente contacto con las artes visuales (Huerta, 2019). Al definir la escritura como dibujo, el alumnado se siente mucho más confiado para enfrentarse a la práctica artística (Figura 1). Quisiera incidir en que no se trata de alumnado universitario de historia del arte o de bellas artes, sino de futuros maestros y maestras de primaria, estudiantes de grado que solamente cursan una asignatura obligatoria de artes (6 créditos, un cuatrimestre) en toda la carrera. Con este ínfimo bagaje preparatorio en arte se enfrentarán después a su trabajo docente en las aulas (Escaño, 2019).
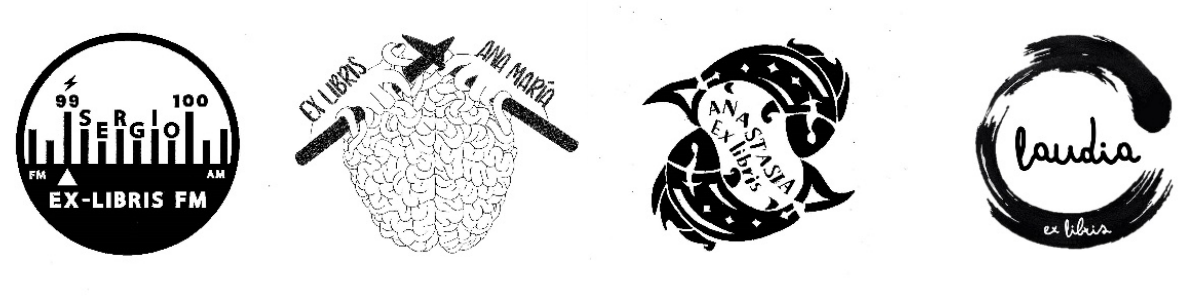

Figura 1. Exlibris diseñados por Sergio Medina, María Bueno, Anastasia Maroto y Claudia Ribes. Fuente: autoría.

Esta primera experiencia consiste en realizar un diseño elaborado a partir del conocimiento de su propia identidad. Mediante una conversación inicial preparatoria y participativa, se decide concentrar la idea en un elemento simbólico (que les identifique) y a partir de aquí se imparten una serie de sesiones en las que se explica el alfabeto como imagen (Menza et al., 2019). 
Posteriormente, cada estudiante realiza su diseño, partiendo de bocetos y dibujos, y compartiendo con el resto sus ideas y avances. Con el fin de activar el debate, se anima a todo el alumnado a presentar en clase su propuesta, y comentarla con sus compañeros. Después damos paso a una sesión de taller en la que se explican aplicaciones informáticas para componer textos y diseñar alfabetos (Ramírez-Escobar, 2020). Esto motiva al grupo de estudiantes, que se ve enfrentado a una relectura de su cotidianeidad, a partir de las tipografías que usan habitualmente (Groupe $\mu$, 1992). Este ejercicio servirá para adecuar la tipografía más adecuada al diseño de su exlibris (Mendelsund, 2015). Llevamos a cabo un proceso diagnóstico, no solo de la actividad, sino también de las acciones que contemplan aspectos teóricos y del conocimiento previo que tenía el alumnado al respecto. Se pasa un cuestionario donde se indaga sobre la relación del estudiantado con la tipografía y sus distintos usos. Hacemos preguntas en torno al uso habitual de las letras como imágenes (Figura 2). A partir del diagnóstico, se organizaron las respuestas desde dos categorías: 1) Conocimiento del alfabeto como formas e imágenes y 2) Procedimientos de diseño.
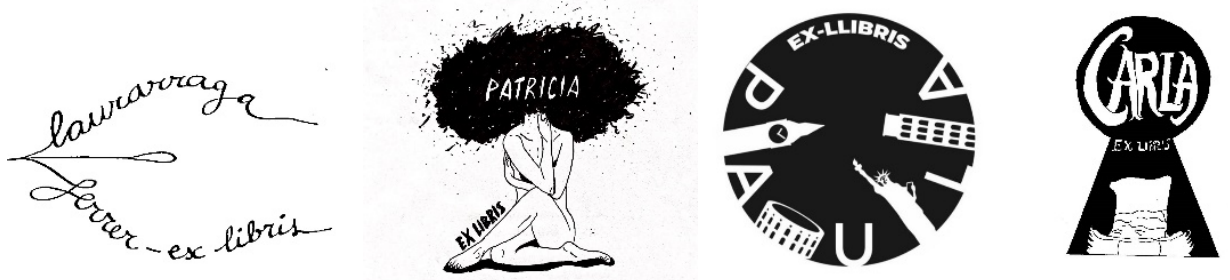

Figura 2. Exlibris diseñados por Laura Raga, Patricia Giménez, Paula Martínez y Carla Boquete. Fuente: autoría.

Categoría "Conocimiento del alfabeto como formas e imágenes". El alumnado plantea una diferenciación entre las escrituras y las letras. Entre las respuestas más recurrentes del diagnóstico se encuentra el desconocimiento de esta 
realidad desde la perspectiva de lo visual, y los prejuicios adquiridos respecto al uso de las letras. Leemos frases que se repiten con frecuencia en el diagnóstico respecto a la pregunta: ¿Te habías planteado antes la importancia de la imagen del alfabeto? A lo que responden:

Nunca me había imaginado la cantidad de posibilidades que tienen las letras al componer los textos. (Estudiante 6)

Llevo toda la vida pensando que era completamente negada para dibujar o crear arte, pero ahora compruebo que puedo defenderme bien. (Estudiante 142)

Componer con textos e imágenes resulta más fácil de lo que pensaba. (Estudiante 70)

Evidenciamos que antes no se habían planteado la escritura como una imagen, y el alfabeto como un escenario visual. La gran mayoría (86\%) ha descubierto sus propias capacidades, y se ha motivado con el ejercicio (Sennett, 2013). En este sentido, la actividad supone un verdadero desafío, ya que incorpora reflexión, identidad, conocimientos y diseño (Huerta, 2016). Se plantea entonces que reflexionen sobre la fuerza de la creatividad artística (Figura 3), y se traslada la discusión hacia las posibilidades que habitan en el campo de la visualidad (Brusatin, 1992).
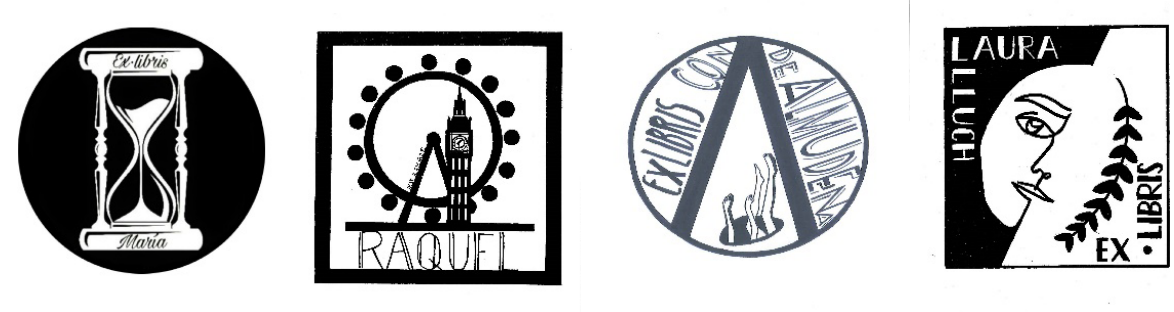

Figura 3. Exlibris diseñados por María Femenía, Raquel Rodríguez, Almudena C. y Laura Lluch. Fuente: autoría. 
Categoría "Procedimientos de diseño". Al inicio, esta categoría genera dudas al alumnado, poco habituado a plantearse soluciones gráficas cuando se trata de textos. Su formación escolar ha tenido únicamente un componente verbal en lo referido al uso de las letras, por eso se encuentran poco familiarizados con el potencial visual de estos símbolos. La reflexión les ayuda a superar estos convencionalismos adquiridos:

Ahora entiendo por qué hay tantos modelos de letra en el menú "tipos". (Estudiante 15)

Me atrae mucho la historia de las civilizaciones, y me ha fascinado poder relacionar los tipos de letra con cada momento histórico. (Estudiante 37)

Cada persona se puede sentir más identificada con una determinada forma de letras. (Estudiante 119)

A partir de los relatos iniciales incorporados a este diagnóstico, se elabora el taller de diseño del exlibris, poniendo en el centro del proceso analítico y crítico la introspección de cada participante, que tendrá que elegir el elemento con el que se siente más identificado (Arévalo et al., 2020). La actividad de diseño y creación de exlibris responde a otras cuestiones relevantes y candentes, como el tipo de aficiones del alumnado, o su vinculación a redes y organizaciones (clubs deportivos, asociaciones culturales, partidos políticos, clubs de fans de cantantes o deportistas). Al identificar esos aspectos consideramos interesante llevar a cabo un proceso de identificación de estereotipos que forman parte de la vida cotidiana del alumnado. Se problematiza a partir de sus propias experiencias, actitudes y formas de mostrarse al mundo (Figura 4). 


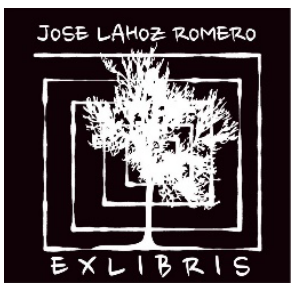

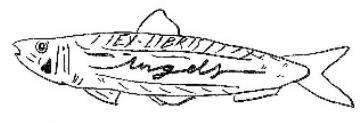

Figura 4. Exlibris diseñados por José Lahoz, Àngels Ribes, María José Sánchez y Elena Rodríguez.

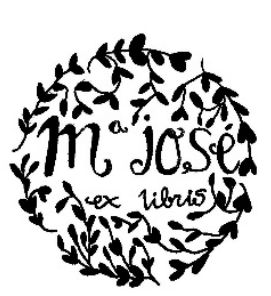

Fuente: autoría.

El taller de exlibris permite que el alumnado identifique elementos de la alfabetidad visual tales como el papel de los textos en los artefactos visuales y la importancia de los símbolos con los que nos identificamos (Contreras, 2019). Tras la presentación de los trabajos, se abre un debate para definir qué aspectos les han resultado más interesantes o motivadores, y para comprobar cómo podríamos aplicar lo aprendido a las clases de primaria, que es donde trabajarán estos docentes en el futuro (Bourriaud, 2009). Tanto el proceso llevado a cabo como los resultados nos permiten evaluar críticamente los trabajos realizados, que son diseños de corte artístico, obras personales implicadas y situadas, que transmiten sentimientos y problemáticas (Huerta, $2020 b$ ). Ha servido asimismo para usar materiales y procedimientos, aplicando elementos del lenguaje visual, con propósitos expresivos.

\section{Caso 2. Proyecto "Ciudad"}

Animamos al alumnado a revisitar su ciudad tomando fotografías, redescubriendo sus espacios habituales mediante las imágenes (Rodríguez y Martínez, 2019). Les invitamos a recopilar tipografías de su entorno cotidiano (Huerta, 2015). Al hacer las fotografías, se sorprenden ante la riqueza 
tipográfica que les deparan estos paseos por lugares conocidos (Barthes, 2009). La creación artística actual mantiene su interés por la imagen de las letras, especialmente desde el marco conceptual, a partir de movimientos como el surrealismo y el situacionismo. Las esquinas de la ciudad se convierten en lugares situados, donde los estudiantes crean piezas a partir del momento vivido. La deriva permite que el paseo sin rumbo adquiera entidad artística (Pérez y Bedoya, 2019). Desde la teoría y el punto de vista de la deriva, cada ciudad contiene en su esencia, ante un vagar urbano aleatorio. La deriva situacionista nos descubre una ciudad cargada de sentido, puesto que el espacio urbano está Ileno de significados (Peralta-Duque y VillescasGuzmán, 2020). En ese momento la letra adquiere relevancia, provocando emociones a través de mapas y mapeos (Alonso-Sanz, 2020). Otro elemento que resulta muy sugerente para los jóvenes universitarios es el denominado urban street art, que utiliza la calle como marco y soporte de sus propuestas creativas. Al hablar del arte en el entorno urbano, reivindicamos el trabajo de artistas como Ken Lum, Jim Sanborn, Robert Montgomery, Jaume Plensa, Tim Etchells, o el colectivo Boa Mistura, incorporándolo a nuestra acción pedagógica para adecuarla a la formación de docentes (Morales, 2019). La artista Jenny Holzer utiliza los textos, generando una actitud en la que adquiere un papel preponderante la tipografía (Figura 5). Muchas de sus obras son textos, composiciones que hablan de violencia, sexualidad, poder, guerra, desde el feminismo, consiguiendo una posición ética desde un discurso que une tecnología, política, religión y filosofía. Al revisar toda esta batería de artistas somos conscientes del poder visual del alfabeto (Castellanos, 2020). De hecho, entre las premisas más importantes de los movimientos de reforma pedagógica, la alfabetización siempre fue un eje primordial (Freire, 2015). 

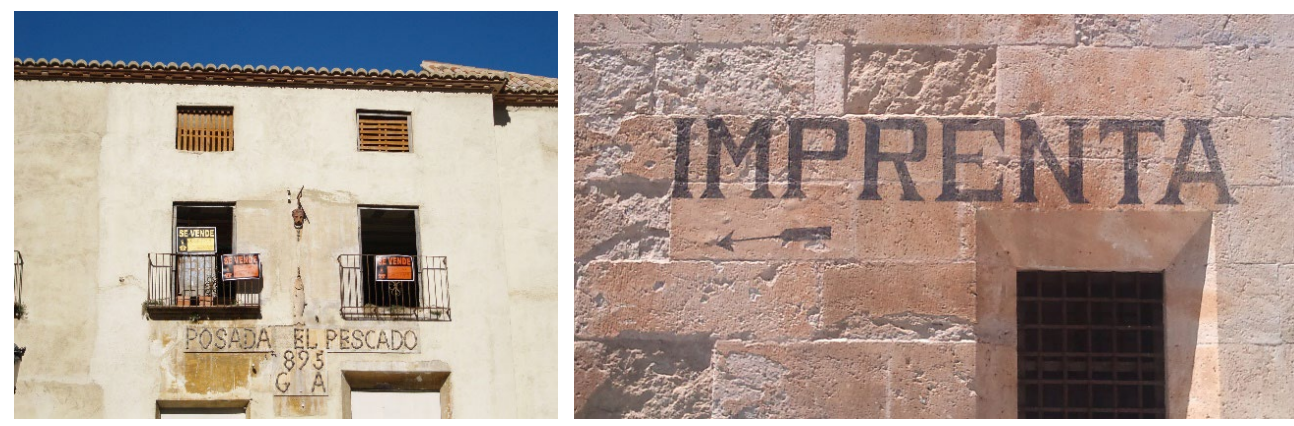

Figura 5. Imágenes de tipografías de la ciudad de Xàtiva tomadas por el alumnado. Fuente: autoría.

Al igual que hicimos en el primer caso, se realiza un diagnóstico para conocer los niveles de conocimiento del alumnado respecto a las representaciones de sus respectivas ciudades. Se les anima a ser "turista en tu propia ciudad", lo cual supone fotografiar entornos cotidianos, buscando especialmente el relato tipográfico, las letras que están presentes en muros y espacios urbanos (Mirzoeff, 2006). De este modo, se establece un debate sobre el papel del alfabeto en la ciudad, las funciones que tienen los letreros (Figura 6), los materiales con los que están realizados, las estéticas que transmiten, la capacidad comunicativa que les es propia (Alves y Pinto, 2019). El diagnóstico arrojó que más del 70\% supo establecer un criterio de adecuación entre la ciudad fotografiada y las letras que dominaban en ese lugar (Viveros, 2020). Al hablar de entornos urbanos se abordan cuestiones como el respecto al patrimonio (Figura 7) y el conocimiento de nuestras realidades (Acebedo, 2019). Algunas de las ideas que emergen en el diagnóstico atienden a estos elementos de la simbología urbana: 
Las veo cada día [las letras], pero nunca las había valorado hasta ahora. (Estudiante 66)

No podía parar de hacer fotos. (Estudiante 115)

Es impresionante la cantidad de letras que encontré en la deriva. (Estudiante 81)

Al preguntar por el concepto de patrimonio, las respuestas son menos precisas que con el concepto anterior, pero incorporan igualmente elementos de reflexión:

No sabía que tenía tan cerca algo que ahora considero valioso. (Estudiante 143)

Si no conocemos nuestro patrimonio, no lo podemos cuidar y valorar. (Estudiante 60)
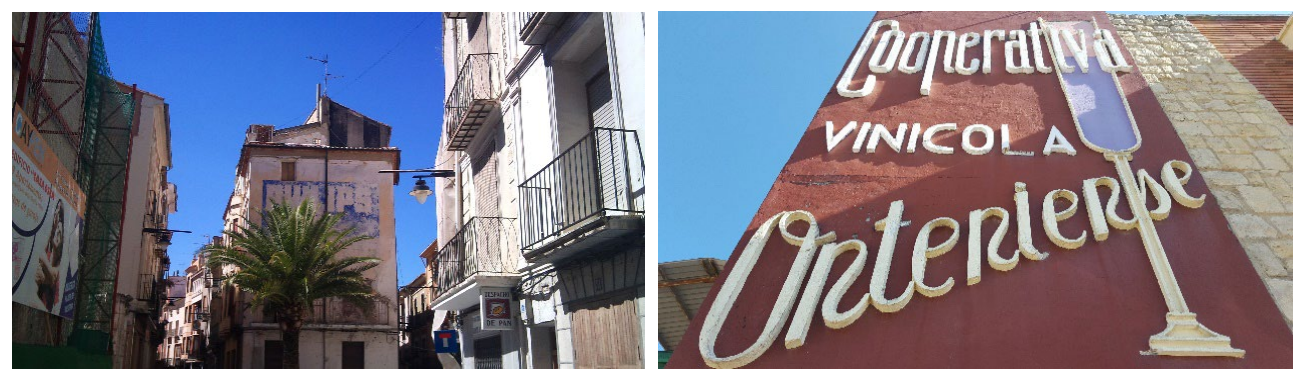

Figura 6. Imágenes de letras fotografiadas por el alumnado en la ciudad de Ontinyent.

El estudio del patrimonio urbano nos lleva también al reconocimiento de las desigualdades. Hacemos referencia a los estereotipos de género desde la materialidad del espacio público, de los usos que hacemos de este espacio compartido. Cuestionamos el imaginario colectivo sobre el género para desarrollar un ejercicio deconstructivo sobre los significados sociales de las imágenes, presentes en el discurso escolar. En la dimensión metodológica intentamos vincular los contenidos con experiencias personales, constatando 
el relato del alumnado respecto a las cosas y formas de representar que son "para niños o niñas", cuestionando estas divisiones o roles. Al finalizar esta actividad, se develan reflexiones por parte del estudiantado que apuntan al cuestionamiento del deber ser social, a la libertad de expresión y a la necesidad de construir escenarios educativos más libres de estereotipos. A través del trabajo artístico se evidencia la valoración por la diversidad y el respeto por la diferencia (Greteman, 2017).
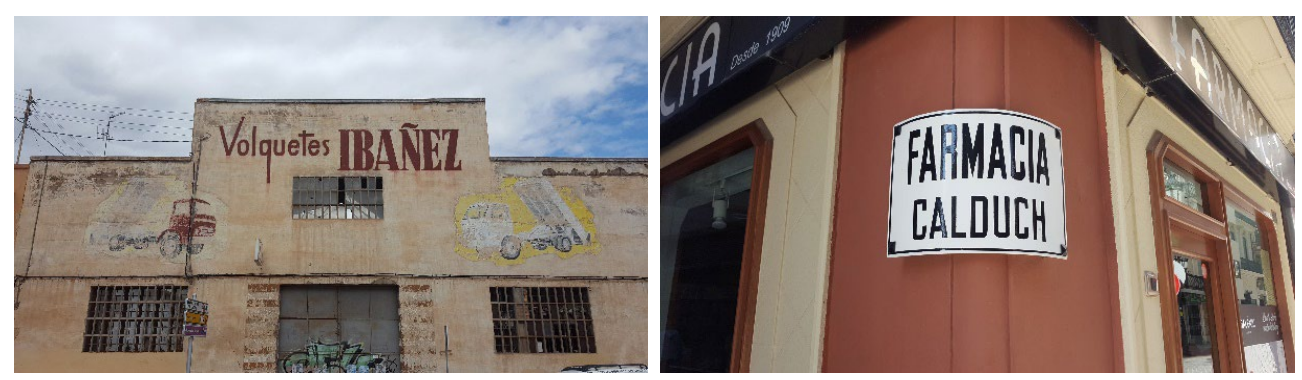

Figura 7. Imágenes de letras de Castelló de la Plana fotografiadas por el alumnado. Fuente: autoría.

La increíble adecuación del alfabeto a cada momento y lugar nos permite reflexionar en un ambiente de trabajo donde se cuestionan los roles sociales, potenciando el respeto hacia la diversidad, fomentando subjetividades libres de tabús y estereotipos, entendiendo lo subjetivo como algo esencial en su formación, atendiendo a situaciones a las que deberán atender, como los procesos de tránsito en personas trans o no binarias, o el bullying hacia el alumnado más indefenso. 


\section{Discusión}

Los talleres realizados en los últimos dos cursos pretenden potenciar el conocimiento de la alfabetidad visual entre el alumnado, teniendo en cuenta que se trata de futuros docentes de Educación Primaria. Los trabajos se articulan a partir de propuestas reflexivas y artísticas, en las que domina la visualidad, atendiendo a la Investigación Educativa Basada en Artes (Rolling, 2017b). Se trata de un modelo que atiende a las denominadas "ARTography", donde el docente se siente al mismo tiempo artista, profesor e investigador (Irwin y O'Donoghue, 2012). De este modo, le damos importancia a los lenguajes artísticos para ir más allá de la oralidad o la escritura, acercándonos a la imagen de las letras desde la alfabetidad visual, lo cual repercute en las maneras mediante las cuales conocemos el mundo, cuestionando los procesos tradicionales de enseñanza y aprendizaje (Munari, 2020).

La investigación permite indagar en las posibilidades de los entornos cotidianos, que otorgan importancia al propio alumnado y sus respectivas realidades (Huerta, 2021). Desarrollamos una actividad reflexiva que se complementa con el proceso de acercamiento a la escritura mediante lenguajes artísticos, potenciando procesos expresivos y reflexivos. Las dos actividades estudiadas como casos estimulan al alumnado a repensar sus dinámicas sociales y a la necesidad de desmarcarse de situaciones de violencia de género, superando roles y estereotipos. Estas actividades fomentan un profesorado más colaborativo y respetuoso, utilizando la actividad artística para mejorar las situaciones de desigualdad.

Los dos casos presentados abordan problemáticas actuales de tipo personal y social desde la investigación artística. Si bien parten de la imagen de las letras, acaban demostrando su validez como detonantes de actitudes y valores. Durante el taller de exlibris algunas alumnas deciden generar su diseño con 
base en un tatuaje que llevan; otros optan por animales de compañía que tienen; también vemos alusiones a sus equipos deportivos favoritos o a instrumentos musicales que tocan, incluso alusiones a festividades con las que se sienten muy identificados (las fallas de Valencia, o la Magdalena en Castelló). Esto nos Ileva a indagar en los gustos y preferencias de su generación, rescatando pequeñas historias, cuestionando los grandes relatos, configurando su propia identidad y las subjetividades colectivas que comparten. Fomentamos experiencias artísticas donde surgen elementos personales que permiten adentrarnos en las realidades del colectivo, avanzando así hacia una educación más inclusiva, incorporando la alfabetidad visual, y desarrollando procesos creativos y reflexivos en torno a temáticas candentes.

\section{Incorporar de forma transversal la inclusión y la diversidad}

Generar un acercamiento a la defensa de los derechos humanos y el respeto a la diversidad mediante el estudio de las imágenes de las letras se puede llevar a cabo incorporando la visualidad del alfabeto a nuestros recursos educativos, considerando los objetos culturales y artísticos elaborados por los movimientos disidentes, así como sus modalidades de creación, presentación, consumo o recepción crítica (Even-Zohar, 1990). Esto significa que no se trataría de objetos autónomos, sino de herramientas que nos permitan comprender la organización de las sociedades contemporáneas y las relaciones sociales de poder que las estructuran, siguiendo los pasos de los estudios culturales (Calvino, 1995). Se trata de no ver en estos artefactos visuales representaciones simbólicas culturales y simples de las políticas en funcionamiento en las comunidades LGTB, sino de subrayar su capacidad de producir y fortalecer identidades colectivas, o renegociar sus significados. La identidad no debe entenderse como algo fijo y esencialista, como una unidad naturalmente estable e inalterada, sino como un concepto estratégico y situado que surge del juego de modalidades específicas de poder. En este sentido, activistas, docentes y artistas pueden unirse en torno 
a una identidad colectiva, cristalizando diferentes demandas. En este sentido, la identidad también es una cuestión de estética, que sirve para la reflexión sobre las identidades culturales LGTB y sus dimensiones políticas. La afirmación de esta sensibilidad se ha convertido así en constitutiva de una identidad artística y cultural específica, empoderándose de todo un panorama visual para superar la marginación. Si bien la constitución de estas comunidades también responde a relaciones de poder que conducen a la reproducción de normas y legitimaciones culturales, lo cierto es que el cuerpo del artista también es vector de emancipación individual con potencial colectivo. Visto así, estas prácticas, que también deben ser consideradas como estrategias militantes, dan fe del lugar único del individuo en las movilizaciones, que siempre tienen una vertiente artística, explorando nuevas perspectivas en la historia de las representaciones de corporalidades marginales o marginadas. Su conocimiento y difusión ayudan a una mejor comprensión de los problemas y las modalidades de la dinámica subjetiva y afectiva en la articulación de corpus iconográficos y teóricos, así como en la construcción de representaciones.

\section{Conclusiones}

Al elaborar un discurso pedagógico gracias al cual formamos al futuro profesorado de primaria incidiendo en la alfabetidad visual, planteamos la necesidad de mejorar su labor docente, ya que desde un mayor acercamiento a las letras como imágenes el alumnado percibe mejor las posibilidades creativas de las letras. Al mismo tiempo, actualizamos el lenguaje y los recursos de las artes visuales pensando en las necesidades escolares actuales, muy impregnadas por el papel predominante de la imagen, así como por los usos de la tecnología digital. Intentamos acercar el mundo del diseño y la tipografía al alumnado universitario, desde una perspectiva múltiple, atendiendo a cuestiones estéticas, culturales, éticas y de implicación social. Gracias a la incorporación de la tipografía en las clases de educación artística conseguimos que buena parte 
del alumnado supere los prejuicios que tiene hacia la práctica de las artes, convirtiendo el estudio y la creación de alfabetos en potenciales creativos de todo el alumnado. Si realmente el alfabeto es una tecnología conocida por el alumnado, que ha aprendido a leer y escribir desde la infancia, la pregunta sería por qué motivo desconoce las posibilidades gráficas de las letras. Esta incapacidad está relacionada con el uso exclusivo de la escritura para el lenguaje verbal, lo cual provoca un verdadero desconocimiento de las letras como imágenes. Intentamos transmitir el concepto de alfabeto como entidad visual de carácter patrimonial, con posibilidades creativas, mediante proyectos sencillos y eficaces como el Taller de Exlibris, o bien la Deriva Tipográfica Urbana, que resultan útiles y motivadores para el alumnado. De este modo, introducimos el conocimiento de las letras como un lenguaje visual, algo que nos permite indagar en cuestiones de identidad y reivindicación social, apostando por la innovación docente y la alfabetidad visual.

\section{Referencias}

Acebedo, L. F. (2019). Cuerpo, ciudad e imaginarios. Intervenciones urbanas desde los sentidos. Kepes, 16(20), 705-741. https://doi.org/10.17151/kepes.2019.16.20.25

Alegría, L., Acevedo, P. y Rojas, C. (2018). Patrimonio cultural y memoria. El giro social de la memoria. Revista Austral de Ciencias Sociales, 34, 21-35. https://doi.org/10.4206/rev. austral.cienc.soc.2018.n34-03

Alonso-Sanz, A. (2020). Una profesora "flâneuse" en París. Cartografías en la formación inicial de docentes. Arte, Individuo y Sociedad, 32(2), 363-386. https://doi.org/10.5209/aris.63670

Álvarez, A. y Cabrera, J. F. (2020). Requerimientos para el diseño de la experiencia de inmersión en laboratorios virtuales. Kepes, 17(22), 277-299. https://doi.org/10.17151/ kepes.2020.17.22.11

Alves, L. A. y Pinto, H. (2019). Educación histórica con el patrimonio: desafiando la formación del profesorado. Revista Electrónica Interuniversitaria de Formación del Profesorado, 22(1). https://doi.org/10.6018/reifop.22.1.356381 
Arévalo, J. M., Mosquera, F. y Cáceres, D. (2020). Emprendimientos radicalmente sustentables: diseños emergentes desde el pensamiento crítico. Kepes, 17(21), 493-536. https://doi. org/10.17151/10.17151/kepes.2020.17.21.17

Arriaga, A., Marcellán, I. y Aberasturi-Apraiz, E. (2018). Mediación crítica en arte y cultura visual. Pulso. Revista de Investigación, 41, 13-17.

Barthes, R. (1986). Lo obvio y lo obtuso. Imágenes, gestos, voces. Paidós.

Barthes, R. (2009). La cámara lúcida. Nota sobre la fotografía. Paidós.

Benjamin, W. (2003). La obra de arte en la época de su reproductibilidad técnica. Ítaca.

Bernal, M. del M. (2016). Los nuevos territorios de la gráfica: imagen, proceso y distribución. Arte, Individuo y Sociedad, 28(1), 71-90. https://doi.org/10.5209/rev_ARIS.2016.v28. $\mathrm{n} 1.47545$

Bourriaud, N. (2009). The Radicant. Lukas \& Sternberg.

Briggs, A. y Burke, P. (2002). De Gutenberg a Internet. Una historia social de los medios de comunicación. Taurus.

Brusatin, M. (1992). Historia de las imágenes. Julio Ollero Editor.

Calvino, I. (1995). Seis propuestas para el próximo milenio. Siruela.

Careri, F. (2005). Walkscapes. El andar como práctica estética. Gustavo Gili.

Castellanos, A. (2020). El Estado-editor en tiempos de alfabetización. Un análisis gráfico de las publicaciones del departamento editorial de la Biblioteca Nacional de Colombia 19301960. Kepes, 17(21), 85-111. https://doi.org/10.17151/10.17151/kepes.2020.17.21.4

Chung, S. K. (2007). Media Literacy Art Education: Deconstructing Lesbian and Gay Stereotypes in the Media. International Journal of Art and Design Education, 26(1), 98-107. https://doi. org/10.1111/j.1476-8070.2007.00514.x

Contreras, F. R. (2019). Estudio filosófico sobre la mirada estética en el diseño. Kepes, 16(19), 11-38. https://doi.org/10.17151/kepes.2019.16.19.2

Dewey, J. (2008). El arte como experiencia. Paidós. 
Dos Reis, J. (2016). Fonte tipográfica Clarim Fonética: um tipo de letra ao som da língua portuguesa. En J. Queiroz (Coord.), Novos lugares para a educação artística: o V Congresso Matéria-Prima (pp. 395-405). Cieba.

Duncum, P. (2008). Holding Aesthetics and Ideology in Tension. Studies in Art Education, 49(2), $122-135$.

Duncum, P. (2015). Transforming Art Education into Visual Culture Education through Rhizomatic Structures. Anadolu Journal of Educational Sciences International, 5(3), 47-64. https://doi. org/10.18039/ajesi.66849

Eisner, E. W. (2004). El arte y la creación de la mente: El papel de las artes visuales en la transformación de la conciencia. Paidós.

Escaño, C. (2019). La mirada como acto político. El cine y otros audiovisuales como herramientas educativas de (re)construcción del mundo. EARI Educación Artística Revista de Investigación, 10, 251-261. https://doi.org/10.7203/eari.1014152

Even-Zohar, I. (1990). Polisystem Theory. Poetics Today, 11(1), 9-26.

Fetter, S. (2019). Letra escolar brasileira. Design de uma família tipográfica para o ensino da escrita manual (tesis doctoral). Universidade Federal do Rio Grande do Sul.

Freire, P. (2015). Pedagogia da autonomia: saberes necessários à prática educativa. Paz e Terra.

Giroux, H. (1990). Los profesores como intelectuales. Hacia una pedagogía crítica del aprendizaje. Paidós.

Greteman, A. J. (2017). Helping Kids Turn Out Queer: Queer Theory in Art Education. Studies in Art Education: A Journal of Issues and Research, 58(3), 195-205.

Groupe $\mu$. (1992). Traité du signe visuel: Pour une rhétorique de l'image. Seuil.

Hamlin, J., \& Fusaro, J. (2018). Contemporary Strategies for Creative and Critical Teaching in the 21st Century. Art Education, 71(2), 8-15.

Hernández, F. (2008). La investigación basada en las artes. Propuestas para repensar la investigación en educación. Educatio Siglo XXI, 26, 85-118.

Hernández, F., \& Sancho-Gil, J. M. (2015). A learning process within an education research group: an approach to learning qualitative research methods. International Journal of Social Research Methodology, 18(6), 651-667. https://doi.org/10.1080/13645579.2015.1049468 
Huerta, R. (2010). Museo Tipográfico Urbano. PUV.

Huerta, R. (2015). La ciudad y sus docentes. Miradas desde el arte y la educación. UOC.

Huerta, R. (2016). The Cemetery as a Site for Aesthetic Enquiry in Art Education. International Journal of Education through Art, 12(1), 7-20. https://doi.org/10.1386/eta.12.1.7_1

Huerta, R. (2017). Transeducar. Arte, docencia y derechos Igtb. Egales.

Huerta, R. (2019). Arte para primaria. UOC.

Huerta, R. (2020a). Arte, género y diseño en educación digital. Tirant lo Blanch.

Huerta, R. (2020b). El diseño de letras como entorno visual para educar en diversidad. Artseduca, 25, 5-22. http://dx.doi.org/10.6035/Artseduca.2020.25.1

Huerta, R. (2021). La imagen como experiencia. McGraw-Hill.

Huerta, R. y Alonso-Sanz, A. (Eds.) (2020). Humanidades digitales y pedagogías culturales. Saberes virales para una nueva educación. UOC.

Huerta, R. y Domínguez, R. (2020). Por una muerte digna para la educación artística. EARI Educación Artística: Revista de Investigación, 11, 9-24. https://doi.org/10.7203/ eari.11.19114

Huerta, R., Domínguez, R. y Barbosa, A. M. (2017). Investigar para educar en diseño y otras urgencias de la educación artística. EARI Educación Artística: Revista de Investigación, 8, 10-23. https://doi.org/10.7203/eari.8.10790

Irwin, R, \& O'Donoghue, D. (2012). Encountering pedagogy through relational art practices. International Journal of Art \& Design Education, 31(3), 221-236.

Lobovikov-Katz, A. (2019). Methodology for Spatial-Visual Literacy (MSVL) in Heritage Education: Application to Teacher Training and Interdisciplinary Perspectives. Revista Electrónica Interuniversitaria de Formación del Profesorado, 22(1). https://doi.org/10.6018/ reifop.22.1.358671

López, J. A. (2019). Visualidad y diseño de comunicación visual, relación cartografías mentalesentorno en la definición de variables de diseño de comunicación visual. Kepes, 16(19), 277-293. https://doi.org/10.17151/kepes.2019.16.19.11

Mendelsund, P. (2015). Qué vemos cuando leemos. Seix Barral. 
Menza, A. E., Rocha, C. A. y Sánchez, W. H. (2019). Modelo de clasificación y visualización de relaciones texto-imagen. Kepes, 16(20), 283-343. https://doi.org/10.17151/ kepes.2019.16.20.12

Miranda, F., Vicci, G. y Ardanche, M. (Comps.) (2017). Educación y visualidad. Investigaciones pedagógicas en contextos hiper-visuales. Udelar.

Mirzoeff, N. (2006). On Visuality. Journal of Visual Culture, 5(1), 53-79.

Morales, J. (2019). Experiencias pedagógicas en el ámbito del diseño para la transición. Estudio de un caso: el proyecto de comunicación del Espai Quiró. Kepes, 16(19), 217-251. https:// doi.org/10.17151/kepes.2019.16.19.9

Munari, B. (2019). Artista y diseñador. Gustavo Gili.

Munari, B. (2020). El arte como oficio. Gustavo Gili.

Pallarès, M. (2014). El legado de Paulo Freire en la escuela de hoy. De la alfabetización crítica a la alfabetización en medios de comunicación. Teoría de la Educación. Revista Interuniversitaria, 26(1), 59-76. http://dx.doi.org/10.14201/teoredu20142615976

Pallarès, M. (2020). Educación humanizada. Una aproximación a partir del legado de Heinrich Rombach. Estudios Sobre Educación, 38, 9-27. https://doi.org/10.15581/004.38.9-27

Pallarès, M. y Lozano, M. (2020). Diálogo con el 'Manifiesto por una pedagogía post-crítica' desde la esperanza como acción social transformadora. Teoría de la Educación. Revista Interuniversitaria, 32(2), 65-79. https://doi.org/10.14201/teri.22451

Panciroli, Ch. (2016). Los bienes culturales como patrimonio educativo. EARI Educación Artística Revista de Investigación, 7, 86-99. https://doi.org/10.7203/eari.7.8158

Peralta-Duque, B. C. y Villescas-Guzmán, L. M. (2020). Significados sociales e institucionales de uso del espacio público. Kepes, 17(22), 109-139. https://doi.org/10.17151/ kepes.2020.17.22.5

Pérez, J. A. y Bedoya, C. M. (2019). La fotografía como herramienta para el desarrollo de la creatividad y la alfabetidad visual: investigación en el aula. Kepes, 16(20), 377-404. https:// doi.org/10.17151/kepes.2019.16.20.14

Ramírez-Escobar, M. F. (2020). Prácticas de visualización en la investigación académica en diseño gráfico. Kepes, 17(22), 77-108. https://doi.org/10.17151/kepes.2020.17.22.4 
Ramon, R. (2017). Pedagogías visuales y artísticas en torno al objeto cotidiano. Artseduca, 18, 30-53.

Ramon, R. (2019). Prácticas artísticas de visualización entre cuerpo y objeto en entornos de mediación pedagógica. Arte, Individuo y Sociedad, 31(13), 509-526. http://dx.doi. org/10.5209/aris.60881

Rodríguez, C. M. y Martínez, H. F. (2019). Dimensiones virtuales de la ciudad: apropiación urbana mediada por el uso de la aplicación digital Pokémon GO. Kepes, 16(19), 317-345. https://doi.org/10.17151/kepes.2019.16.19.13

Rolling, J. H. (2017a). Arts-Based Research in Education. In P. Leavy (Ed.), Handbook of ArtsBased Research (pp. 493-510). Guilford.

Rolling, J. H. (2017b). Art + Design Practice as Global Positioning System. Art Education, 70(6), 4-6.

Said-Valbuena, W. (2019). Prefigurar, co-crear, entretejer. Diseño, creatividad, interculturalidad. Arte, Individuo y Sociedad, 31(1), 111-129. https://doi.org/10.5209/ARIS.59369

Sancho-Gil, J. M. y Hernández, F. (2018). La profesión docente en la era del exceso de información y la falta de sentido. RED. Revista de Educación a Distancia, 56. 10.6018/red/56/4

Santamaría, A. (2019). Alta cultura descafeinada. Situacionismo low cost y otras escenas del arte en el cambio de siglo. Siglo XXI.

Sennett, R. (2013). El artesano. Anagrama.

Stake, R. E. (2005). Investigación con estudio de casos. Morata.

Viveros, C. E. (2020). Fotografía, autobiografía y autoetnografía en Mitos: el cuadrado del tiempo. Kepes, 17(22), 465-500. https://doi.org/10.17151/kepes.2020.17.22.17

Yin, R. (1994). Case Study Research: Design and Methods. Sage.

Zafra, R. (2017). El entusiasmo. Precariedad y trabajo creativo en la era digital. Anagrama.

Cómo citar: Huerta, R. (2022). El alfabeto latino como estímulo para la alfabetidad visual. Diseño, formación del profesorado y derivas tipográficas urbanas. Revista KEPES, 19(25), 363-391. https://doi.org/10.17151/ kepes.2022.19.25.13 